\title{
Comparison of smith-petersen osteotomy, pedicular subtraction osteotomy, and poly-segmental wedge osteotomy in treating rigid thoracolumbar kyphotic deformity in ankylosing spondylitis a systematic review and meta-analysis
}

Xumin $\mathrm{Hu}^{1}$, Ashish Jung Thapa ${ }^{2}$, Zhaopeng Cai ${ }^{1}$, Peng Wang ${ }^{1}$, Lin Huang ${ }^{1}$, Yong Tang ${ }^{1}$, Jichao Ye ${ }^{1}$, Keng Cheng ${ }^{1}$ and Huiyong Shen ${ }^{1 *}$

\begin{abstract}
Background: This study aimed to compare Smith-Petersen osteotomy (SPO), poly-segmental wedge osteotomy (PWO) and pedicular subtraction osteotomy (PSO) in patients with rigid thoracolumbar kyphosis primarily caused by ankylosing spondylitis. The efficiency, efficacy and safety of these three osteotomies have not been compared systematically, and no illness-oriented surgical type selection strategy for the treatment of ankylosing spondylitis related to non-angular kyphosis has been reported.

Methods: The inclusion and exclusion criteria were defined, and 19 electronic databases were searched for eligible studies without language limitations. For the included studies, data extraction, bias analysis, heterogeneity analysis and quantitative analysis were performed to analyze the correction of kyphosiskyphosis and the incidence of complications.

Results: Nine comparative studies that met the standards were included with a total of 539 patients that underwent SPO $(n=120)$, PWO $(n=119)$, or PSO $(n=300)$. The correction of kyphosis by PSO was $8.74^{\circ}$ [95 \% Cl: 0.7-16.78] greater than SPO. The correction of kyphosis by PWO was 13.88 [95 \% Cl: 9.25-18.51] greater than SPO. For local biomechanical complications, the pooled risk ratio of PWO to PSO was 1.97 [95 \% Cl: 1.03-3.77]. For blood loss, PSO was $806.42 \mathrm{ml}$ [95 \% Cl: 591.72-1021.12] greater than SPO and $566.76 \mathrm{ml}[95 \% \mathrm{Cl}:$ 129.80-1003.72] greater than PWO.
\end{abstract}

Conclusions: To treat rigid thoracolumbar kyphosis, PSO showed higher efficiency and efficacy than SPO, and PWO had a higher efficacy than SPO. The risk of local biomechanical complications was greater in PWO than PSO. Bleeding was more severe in PSO than in SPO or PWO. The incidence of neural complications and systemic complications was similar.

Keywords: Smith-petersen osteotomy, Pedicular subtraction osteotomy, Poly-segmental wedge osteotomy, Ankylosing spondylitis, Kyphosis

\footnotetext{
* Correspondence: shenhuiyong@aliyun.com

'Department of Spine Surgery, Sun Yat-Sen Memorial Hospital, Sun Yat-Sen

University, 107\# Yanjiangxi Road, Guangzhou 510120, P.R. China

Full list of author information is available at the end of the article
} 


\section{Background}

Ankylosing Spondylitis (AS), a type of chronic disease that involves the axial skeleton, causes severe thoracolumbar kyphotic deformity (TKD). AS makes it difficult for patients to see forward, stand straight and maintain a comfortable posture. Some patients even suffer from dyspnea or other serious complications due to chest compression $[1,2]$. Therefore, it is necessary to perform corrective surgeries to help restore spine curvature and visual function $[3,4]$.

To treat non-angular kyphosis, there are two categories of frequently used surgery. The first, called opening osteotomy (OO), is characterized by "opening" of the anterior column. The Smith-Petersen [5] osteotomy and its modified versions developed by Chapelle [6], Briggs [7], Wilson [8] and Simmons [2] are common choices. SPO only works on one or two segments, so the anterior longitudinal ligament (ALL) and the aorta may be ruptured under highly concentrated stress. In 1982, Zielke [9] increased the segments to three or more. The "elongated SPO" allocates the stress to each segment evenly and is called poly-segmental wedge osteotomy.

The second category is "closing" the posterior column by tri-column osteotomy within one vertebra and is thus termed the closing osteotomy (CO), Thomassen Osteotomy or pedicular subtraction osteotomy; it was first described by Thomassen [10] in 1986. Modified versions of this procedure, such as the "egg-shell" osteotomy and transpedicular bivertebrae wedge osteotomy, are classified as closing osteotomies.

Both opening and closing osteotomies are effective in the treatment of non-angular kyphosis. Several noncomparative clinical trials have attempted to describe the efficacy of kyphosis correction and risk, but many controversies remain. Until now, there was neither a randomized controlled trial (RCT) nor a quantitative meta-analysis on this subject, so the evidence was insufficient to determine which strategy is better. The class of available evidence is not superior to level-3 according to "Oxford 2011 Levels of Evidence" [11], which was established by the OCEBM Levels of Evidence Working Group.

It is important to realize that simply summarizing each individual study without weighting them or equalizing to a baseline as was done in some articles is unacceptable. A meta-analysis of pairwise comparative studies would weight each study by its quality and effectively solve the baseline problem. In order to meet this purpose, raise the level of evidence and highlight some unapparent outcomes by the pile-up effect, the authors of this study intended to perform a meta-analysis to compare SmithPetersen osteotomy, poly-segmental wedge osteotomy and pedicular subtraction osteotomy from the aspects of efficacy (general correction of kyphosis), efficiency (per level), and safety (complications) in kyphosis correction.

\section{Methods}

\section{Inclusion and exclusion criteria}

Studies meeting all inclusion criteria but none of the exclusion criteria were enrolled. The criteria consisted of 4 parts: type of intervention, type of study, type of participant and type of outcome. A comparison between opening osteotomy and closing osteotomy was acceptable. Controlled studies were eligible. Blindness and allocation concealment were not restricted. Rigid thoracolumbar kyphosis caused by AS or other diseases was eligible. Neither non-rigid nor non-thoracolumbar kyphosis was included. Studies containing patients older than 80 years old or who had an accompanying severe systemic disease like organ failure, malignant tumors or psychosis were excluded, and studies in which patients did not sign consent forms were also excluded. Correction of kyphosis and the incidence of complications were the outcomes of interest. Correction of kyphosis included local correction and that of the whole spine. All information about complications had to be included.

\section{Search}

Without confining the language type, the first two authors filtered the articles by the keywords of osteotomy, osteotomies, ankylosing spondylitis, rigid, fixed, kyphotic, kyphosis, deformity, deformities, thoracic, lumbar, thoracolumbar, sagittal, imbalance, correction, and corrective in databases such as PubMed, Web of Science, Journal Citation Reports (JCR), Derwent Innovations Index, BIOSIS Previews, MEDLINE, Essential Science Indicators (ESI), EMBASE, OVID, ACP Journal Club, Cochrane Central Register of Controlled Trials, Cochrane database of systematic reviews, Cochrane Methodology Register, Database of Abstract of Reviews of Effects, Health Technology Assessment, NHS Economic Evaluation Database, China National Knowledge Infrastructure (CNKI), VIP, and Wanfang Data. The third author was prepared to make a judgement call if any divergence occurred. The date was up to 2015/7/27.

\section{Data extraction and assessment of study quality}

The authors extracted the following information independently and contacted the original authors in case some critical data were found to be lacking: date, study type, patient quantity, gender, age, follow-up period, osteotomy type, operative segments, correction of $\mathrm{ky}$ phosis, type and incidence of complications. The second step was the assessment of their quality by means of Cochrane Collaboration's Tool for Assessing Risk of Bias [12] for RCT, and The Newcastle-Ottawa Scale (NOS) [13] for non-RCT. Subgroup analysis and sensitivity analysis were performed if necessary. 


\section{Heterogeneity and quantitative analysis}

Heterogeneity analysis was used to evaluate the differences between studies that were large or small, and the $\mathrm{Chi}^{2}$ and $\mathrm{I}^{2}$ statistics were used in this step. A $p$ value from the Chi square test less than 0.05 and an I square greater than $50 \%$ were considered substantial. Only comparative studies were pooled. The fixed and random mode was used to merge homogenous and heterogeneous data. Subgroup analysis was performed if necessary. The level of the test $(\alpha)$ was set as 0.05 . Continuous variables were merged by the general variance-based method. The risk ratio (RR) of dichotomous variables was merged by the Mantel-Haenszel method. All analyses were realigned using Review Manager (Version 5.3) [14] software from the Cochrane Collaboration.

\section{Results and discussion Search results}

The electronic database search and an additional hand search initially yielded 116 citations. All full texts were downloaded from the original database. Of these, 48 did not meet the criteria of participants, 35 were not the correct study type, and 22 did not meet the intervention criteria. Only 9 [15-23] papers were used for the final analysis (Fig. 1). Of these 9 included papers, 8 were retrospective cohort studies and 1 [15] was a conference article. All were published studies, and none were ongoing.

\section{Data extraction and bias analysis}

The 9 studies included 539 patients and 3 types of osteotomies, such as SPO $(n=120)$, PWO $(n=119)$ and PSO $(n=300)$, without the involvement of other modified surgical types, such as the "egg-shell" osteotomy. The cases of SPO consisted of 111 single-level and 9 double-level. However, each PSO was operated in a single level. Four studies $[17,19,20,23]$ reported that PSO was used more often to treat patients with severe stiffness.

The descriptive data of the studies are shown in Table 1. Local biomechanical complications were defined as biomechanical imbalance or instability of the local bone-instrument complex, such as vertebral body translation, pedicle fracture, pedicle screw loosening, instrument breakage, nonunion, and anterior cortex fracture. Neural complications included transient and permanent injury of the radicular and spinal cord. Others, such as superior mesenteric artery syndrome, abdominal compartment syndrome, paralytic ileus, intestinal perforation, dyspnea, pneumonia, cardiac infarction, visual field defect and infection, were classified into systemic complications. The Newcastle-Ottawa Scale was applied to assess whether the biases were too large to combine. The result was encouraging because each text received at least 4 points (median quality). The results are presented in Table 2 .

\section{Correction of kyphosis}

The pooled data of kyphosis correction is presented in Fig. 2. In the comparison of SPO and PSO, the former

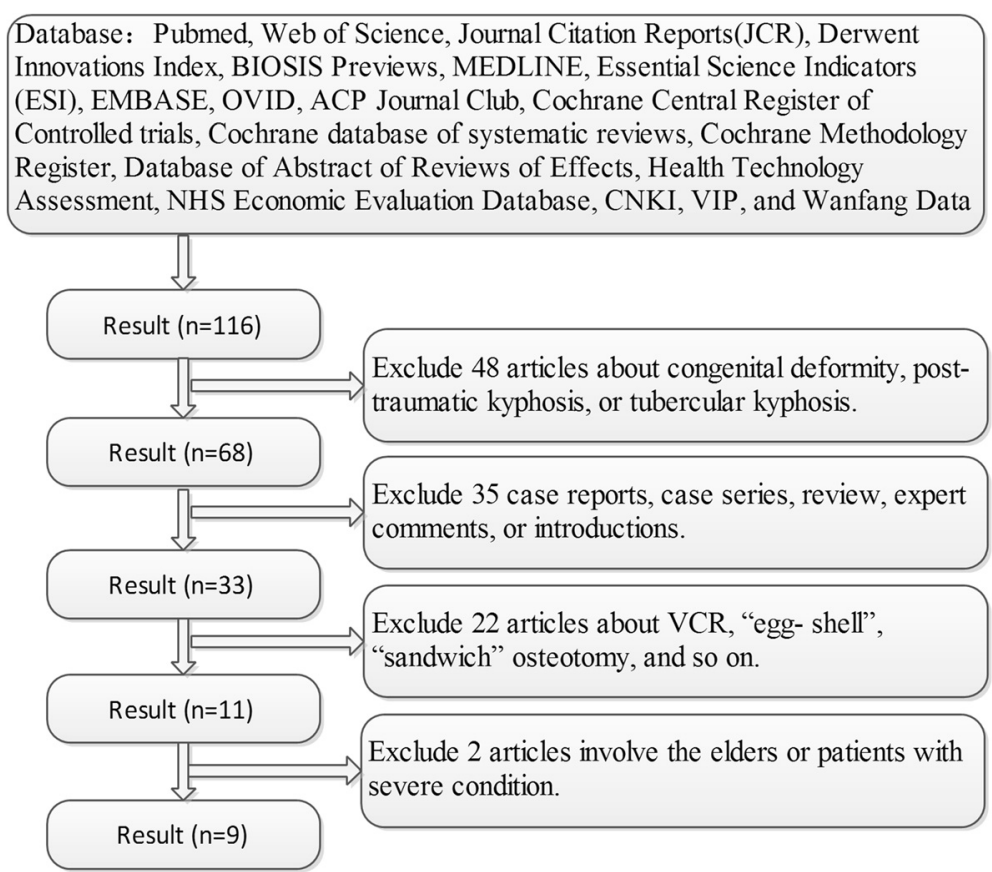

Fig. 1 Flowchart of search strategy and results. Information: 9 articles were filtered out from 116 original literatures 
Table 1 Descriptive Data of Studies Included

\begin{tabular}{|c|c|c|c|c|c|c|c|c|}
\hline Study & Group & $\mathrm{n}$ & $\begin{array}{l}\text { Age (range) } \\
\text { /year }\end{array}$ & M:F & Level (NO.) & $\begin{array}{l}\text { Correction of } \\
\text { lordosis } /^{\circ}\end{array}$ & $\begin{array}{l}\text { Follow up } \\
\text { (range) /Month }\end{array}$ & Complication (NO.) \\
\hline \multirow[t]{2}{*}{$\begin{array}{l}\text { Lazennec } \\
15\end{array}$} & SPO & 19 & $43.5(32-61)$ & 26:5 & $\begin{array}{l}\text { T12-L1 (1); L2-L3 (7); L3-L4 (9); } \\
\text { L4-L5 (2) }\end{array}$ & $41.1 \pm 5.8$ & - & $\begin{array}{l}\text { Dural tear (4); Translation of caudal segment (5); Anterior cortex (1); } \\
\text { Unstable fixation (4); Transient neural injury (6); paralysis (1); Narrowing } \\
\text { of vertebral canal (1) }\end{array}$ \\
\hline & PSO & 12 & & & L1 (1); L2 (7); L3 (4) & $47.4 \pm 4.5$ & & Nonunion (1); Transient neural symptom (3); Secondary displacement (2) \\
\hline \multirow[t]{2}{*}{$\mathrm{Qiu}^{20}$} & PWO & 23 & $36(25-56)$ & 49:5 & T12-L4 (23) & $44 \pm 12$ & $20(11-45)$ & Dural tear (1); Pedicle fractures (1); Insufficient folding (4) \\
\hline & PSO & 31 & & & L2 or L3 (31) & $36 \pm 19$ & & Dural tear (1); Insufficient folding (2); Transient neural symptom (2) \\
\hline \multirow[t]{2}{*}{ Willems $^{27}$} & PWO & 20 & $46.1(21-82)$ & $88: 22$ & - & - & 12 & $\begin{array}{l}\text { Dural tear (5); Pedicle fractures (1); Insufficient folding (2); Deep infection } \\
\text { (3); Neural damage (1); Instrumentation failure (4); }\end{array}$ \\
\hline & PSO & 62 & & & & & & $\begin{array}{l}\text { Dural tear (12); Pedicle fractures (4); Superficial infection (4); Deep infection } \\
\text { (5); Neural damage (6); Instrumentation failure (10); } \text { others }^{a}(8)\end{array}$ \\
\hline \multirow[t]{3}{*}{$\mathrm{Cho}^{5}$} & SPO & 16 & $40.1 \pm 11$ & $23: 7$ & Single (7); Double (9) & $24.9 \pm 10.6$ & $55.2(24-276)$ & \multirow{2}{*}{$\begin{array}{l}\text { Dural tear (1); DVT (1); Transient neural symptom (1); Superficial infection } \\
\text { (3); Deep infection (1); Sagittal imbalance (4); nonunion (3) }\end{array}$} \\
\hline & PWO & 14 & & & $\begin{array}{l}\text { Triple (9); quadruple (3); } \\
\text { quintuple (2) }\end{array}$ & $33.0 \pm 9.2$ & & \\
\hline & PSO & 41 & $54.5 \pm 11.7$ & 33:8 & - & $31.7 \pm 9.0$ & $49.4(24-85.2)$ & $\begin{array}{l}\text { Dural tear (3); DVT (2); Transient neural symptom (3); Superficial infection } \\
\text { (1); nonunion (3); others }{ }^{b} \text { (3) }\end{array}$ \\
\hline Chang $^{4}$ & SPO & 66 & $34.8(17-55)$ & 102:15 & L1-L2 (5); L2-L3 (55); L2-L4 (6) & $40 \pm 14$ & $43.2(25.2-63.6)$ & $\begin{array}{l}\text { Dural tear (4); Superficial infection (1); Transient neural symptom (3); } \\
\text { Nonunion (3); Screw loosing (1); Kyphosis aggravation (2); others }{ }^{c}(13)\end{array}$ \\
\hline Study & Group & $n$ & $\begin{array}{l}\text { Age (range) } \\
\text { /year }\end{array}$ & M:F & Level (No.) & $\begin{array}{l}\text { Correction of } \\
\text { lordosis } /^{\circ}\end{array}$ & $\begin{array}{l}\text { Follow up (range)/ } \\
\text { Month }\end{array}$ & Complication (No.) \\
\hline Chang $^{4}$ & PSO & 51 & $34.8(17-55)$ & 102:15 & L2 (47); L3 (4) & $38 \pm 11$ & $43.2(25.2-63.6)$ & $\begin{array}{l}\text { Dural tear (3); Superficial infection (1); Transient neural symptom (3); } \\
\text { Nonunion (3); Screw loosing (3); Kyphosis aggravation (3); } \text { others }^{c}(4)\end{array}$ \\
\hline \multirow[t]{2}{*}{ Zhu ${ }^{29}$} & PWO & 32 & $35.2(22-60)$ & $29: 3$ & $\begin{array}{l}\mathrm{T} 11-\mathrm{L} 4(8) ; \mathrm{T} 12-\mathrm{L} 4(21) ; \mathrm{T} 12-\mathrm{L} 5 \\
\text { (3) }\end{array}$ & $39.1 \pm 7.8$ & At least 3 & Dural tear (4); Screw loosing (2); Transient neural symptom (1); others $^{\mathrm{d}}$ (5) \\
\hline & PSO & 61 & $37.8(20-86)$ & 53:8 & T12 (2); L1 (11); L2 (30); L3 (18) & $37.1 \pm 3.8$ & & $\begin{array}{l}\text { Dural tear (1); Screw loosing (3); Secondary displacement (2); Fatal } \\
\text { Bleeding > } 4000 \mathrm{ml}(5) \text {; Transient neural symptom (4); } \text { others }^{\mathrm{d}}(5)\end{array}$ \\
\hline \multirow[t]{3}{*}{ Arun $^{1}$} & SPO & 10 & $54.7(40-74)$ & 26:5 & L3-L4 (10) & $19 \pm 11.6$ & $60(24-240)$ & $\begin{array}{l}\text { Dural tear (2); Aorta damage (1); Nerve root injury (1); nonunion (1); } \\
\text { Epidural hematoma (1) }\end{array}$ \\
\hline & PWO & 9 & & & L2-L5 (9) & $30 \pm 6.2$ & & Dural tear (1); Superficial infection (1); Epidural hematoma (1) \\
\hline & PSO & 12 & & & L3 (12) & $38 \pm 5.4$ & & $\begin{array}{l}\text { Dural tear (1); Nerve root injury (1); Superficial infection (1); Epidural } \\
\text { hematoma (1) }\end{array}$ \\
\hline \multirow[t]{2}{*}{ Zhu $^{30}$} & PWO & 19 & $27(21-40)$ & $16: 3$ & $\begin{array}{l}\mathrm{T} 11-\mathrm{L} 4(4) ; \mathrm{T} 12-\mathrm{L} 4(14) ; \mathrm{T} 12-\mathrm{L} 5 \\
(1)\end{array}$ & $38.6 \pm 12.8$ & At least 12 & Dural tear (2); Transient neural symptom (1); \\
\hline & PSO & 31 & $36(22-54)$ & $26: 5$ & L1 (9); L2 (14);L3 (8) & $42.6 \pm 15.7$ & & Dural tear (1); Transient neural symptom (3); Neural damage (1) \\
\hline
\end{tabular}

Note: ${ }^{a}$ indicates pulmonary embolism, blindness, gastrointestinal perforation, or death; ${ }^{b}$ myocardial infarction or dyspnea; ${ }^{c}$ indicates pneumonia or enteroplegia. Age (range), mean and range of age of patients; M:F, ratio of male to female; Level, the level of osteotomy operated; NO., the number of osteotomy segment or happening of complication; SPO, Smith-Petersen osteotomy; PWO, poly-segmental Wedge Osteotomy; PSO, pedicle subtraction osteotomy; ${ }^{\mathrm{d}}$ gastrointestinal perforation, enteroplegia, or Syndrome of superior mesenteric artery 
Table 2 Assessment of studies

\begin{tabular}{|c|c|c|c|c|c|c|c|c|c|}
\hline Categories & Items & Lazennec $^{15}$ & $\mathrm{Qiu}^{20}$ & Willems $^{27}$ & $\mathrm{Cho}^{5}$ & Chang $^{4}$ & Zhu $^{29}$ & Arun $^{1}$ & Zhu ${ }^{30}$ \\
\hline \multirow[t]{4}{*}{ Selection } & $\begin{array}{l}\text { Representativeness of the Exposed } \\
\text { Cohort }\end{array}$ & Not described & Not described & Not described & Not described & Not described & Not described & Not described & Not described \\
\hline & $\begin{array}{l}\text { Selection of the Non-Exposed } \\
\text { Cohort }\end{array}$ & $\begin{array}{l}\text { The same } \\
\text { population }\end{array}$ & $\begin{array}{l}\text { The same } \\
\text { population }\end{array}$ & $\begin{array}{l}\text { The same } \\
\text { population }\end{array}$ & $\begin{array}{l}\text { The same } \\
\text { population }\end{array}$ & $\begin{array}{l}\text { The same } \\
\text { population }\end{array}$ & $\begin{array}{l}\text { The same } \\
\text { population }\end{array}$ & $\begin{array}{l}\text { The same } \\
\text { population }\end{array}$ & $\begin{array}{l}\text { The same } \\
\text { population }\end{array}$ \\
\hline & Ascertainment of Exposure & $\begin{array}{l}\text { Surgical } \\
\text { document }\end{array}$ & $\begin{array}{l}\text { Surgical } \\
\text { document }\end{array}$ & $\begin{array}{l}\text { Surgical } \\
\text { document }\end{array}$ & $\begin{array}{l}\text { Surgical } \\
\text { document }\end{array}$ & $\begin{array}{l}\text { Surgical } \\
\text { document }\end{array}$ & $\begin{array}{l}\text { Surgical } \\
\text { document }\end{array}$ & $\begin{array}{l}\text { Surgical } \\
\text { document }\end{array}$ & $\begin{array}{l}\text { Surgical } \\
\text { document }\end{array}$ \\
\hline & $\begin{array}{l}\text { Outcome of Interest Was Not } \\
\text { Present at Start of Study }\end{array}$ & Sure & Sure & Sure & Sure & Sure & Sure & Sure & Sure \\
\hline Comparability & Comparability of Cases and Control & $\begin{array}{l}\text { With } \\
\text { confounding } \\
\text { factors }\end{array}$ & $\begin{array}{l}\text { With } \\
\text { confounding } \\
\text { factors }\end{array}$ & $\begin{array}{l}\text { With } \\
\text { confounding } \\
\text { factors }\end{array}$ & $\begin{array}{l}\text { With } \\
\text { confounding } \\
\text { factors }\end{array}$ & $\begin{array}{l}\text { With } \\
\text { confounding } \\
\text { factors }\end{array}$ & $\begin{array}{l}\text { With } \\
\text { confounding } \\
\text { factors }\end{array}$ & $\begin{array}{l}\text { With } \\
\text { confounding } \\
\text { factors }\end{array}$ & $\begin{array}{l}\text { With } \\
\text { confounding } \\
\text { factors }\end{array}$ \\
\hline \multirow[t]{3}{*}{ Outcome } & Assessment of Outcome & Reliable & Reliable & Reliable & Reliable & Reliable & Reliable & Reliable & Reliable \\
\hline & $\begin{array}{l}\text { Was Follow-Up Long Enough for } \\
\text { outcomes to occur? }\end{array}$ & Not described & Yes & Yes & Yes & Yes & Yes $^{\mathrm{a}}$ & Yes & Yes \\
\hline & Loss of Follow Up & Full follow-up & Not described & Full follow-up & Full follow-up & Full follow-up & Full follow-up & Full follow-up & Full follow-up \\
\hline Score & & 5 & 4 & 6 & 6 & 6 & 5 or $6^{b}$ & 6 & 6 \\
\hline
\end{tabular}

Note: ${ }^{\text {a }}$ Zhu reported at least 3-month follow-up which satisfied the observation of immediate correction of lordosis and neural symptom but not bony union; ${ }^{\mathrm{b}} 5$ points for assessment of bony union and 6 for lordosis correction. The full mark is 8 points 


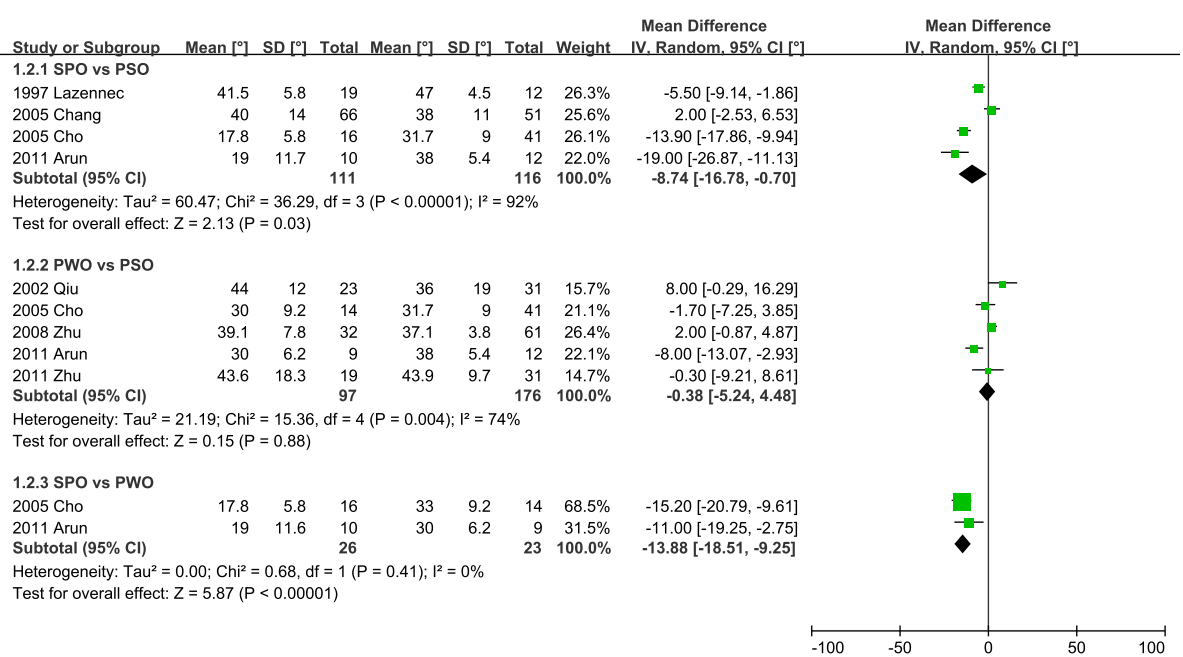

Fig. 2 Comparison of three types of osteotomy on kyphosis correction among SPO, PSO and PWO. Information: Both PSO and PWO had bigger correction angle than SPO

correction of kyphosis ranged from $19^{\circ}$ to $41.5^{\circ}$ with a mean of $35.2^{\circ}$, and PSO ranged from $31.7^{\circ}$ to $48^{\circ}$ with a mean of $36.7^{\circ}$. The correction angle of SPO was $8.74^{\circ}$ [ $95 \%$ CI: 0.7-16.78] lower than PSO ( $\left.{ }^{2}=92 \%\right)$. In the comparison between PWO and PSO, the former ranged from $30^{\circ}$ to $44^{\circ}$ with a mean of $39.0^{\circ}$, while PSO ranged from $36^{\circ}$ to $43.9^{\circ}$ with a mean of $36.1^{\circ}$. The correction angle of PWO was similar to PSO (mean difference: $0.38^{\circ}$ [95 \% CI:-4.485.24]. In the comparison of SPO and PWO, the former ranged from $17.8^{\circ}$ to $19^{\circ}$ with a mean of $18.3^{\circ}$, and PWO ranged from $30^{\circ}$ to $33^{\circ}$ with a mean of $31.8^{\circ}$. The SPO was $13.88^{\circ}$ [95 \% CI: 9.25-18.51] lower than PWO $\left(\mathrm{I}^{2}=0\right)$.

\section{Complications}

\section{Local biomechanical complications}

Seven articles reported local biomechanical complications (Fig. 3). The authors excluded Cho's paper because it contained non-rigid congenital and degenerative kyphosis. In the comparison of SPO and PSO, the RR ranged from 1.03 to 11.40 with a pooled value of 2.74 [95 \% CI: 0.91-8.20]. In the comparison of PWO and PSO, the RR ranged from 1.00 to 14.67 with a pooled value of 1.97 [95 \% CI: 1.03-3.77] $\left(\mathrm{I}^{2=} 48 \%\right)$.

\section{Blood Loss}

Three articles $[15,16,18]$ did not record blood loss, or it was recorded improperly. In the comparison of SPO and PSO, the blood loss of the former ranged from $750 \mathrm{ml}$ to $1101 \mathrm{ml}$ with a mean of $1115 \mathrm{ml}$, and PSO ranged from $1400 \mathrm{ml}$ to $1915 \mathrm{ml}$ with a mean of $2132 \mathrm{ml}$. The blood loss of PSO was $806.42 \mathrm{ml}$ [95 \% CI: $519.72-1021.12]$ greater than SPO $\left(\mathrm{I}^{2}=11\right)$. In the comparison of PWO and $\mathrm{PSO}$, the former ranged from $950 \mathrm{ml}$ to $1392 \mathrm{ml}$ with a mean of $1076 \mathrm{ml}$, and PSO

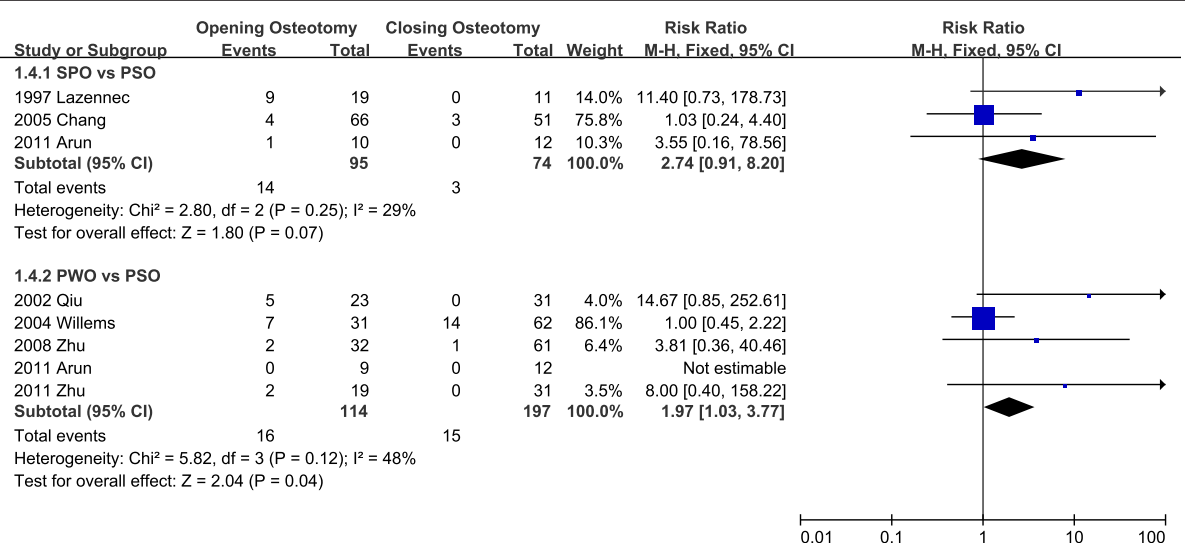

Fig. 3 Title: Comparison of local biomechanical complications in SPO, PSO, and PWO; CI. Information: The risk ratio of PWO to PSO was 1.97 and significant 
ranged from $1200 \mathrm{ml}$ to $2617 \mathrm{ml}$ with a mean of $1872 \mathrm{ml}$. The blood loss of PSO was $566.76 \mathrm{ml}$ [95 \% CI: 129.80-1003.72] greater than PWO $\left(\mathrm{I}^{2}=78\right)$. Generally speaking, the amount of bleeding presented in Fig. 4 was more severe in closing osteotomy than in opening osteotomy.

\section{Dural tear, neural complications, and systemic complications}

Seven articles reported the incidence of dural tear, neural complications, and systemic complications. As is shown in Fig. 5, the pooled RR of dural tear was 1.91 [95 \% CI: 1.04-3.51], and the $\mathrm{p}$ value was less than $0.05\left(\mathrm{I}^{2}=0\right)$. The RR of systemic complications was 1.46 (not significant, $\left.\mathrm{I}^{2}=11 \%\right)$. The $\mathrm{RR}$ of neural complications was 0.6 (not significant, $\mathrm{I}^{2}=0$ ). The authors attempted to separate radicular and spinal injuries to perform subgroup analysis but failed due to a shortage of suitable studies.

\section{Discussion}

Four pooled studies used opening osteotomy (SPO or $\mathrm{PWO}$ ) to treat mild-rigid spine, and closing osteotomy (PSO) to severe-rigid spine, because the anterior column of mild-rigid spine can be bent backwards easily in the process of "opening", while the stiffness of the severerigid spine can only accept "cutting and closing" in a closing osteotomy. This point of view is generally recognized as consensus by most surgeons. In this research, the stiffness of spine was simply divided into three categories based on their degree of stiffness and the surgical type doctors considered appropriate. For the very soft or very rigid kyphosis, doctors were already able to choose the suitable operation easily based on their expertise as mentioned, so the operation selection guidance for those cases was not necessary. However, they usually felt hesitation about the intersectional stiffness between mild and severe since both opening and closing methods seemed good to use, therefore we define this state of stiffness as "median-rigid kyphosis" These cases are actually confusing to surgeons attempting to choose a suitable method.

The efficiency of kyphosis correction in osteotomy can be defined as the correction of kyphosis per surgical level. As described above, the kyphosis correction of PSO was larger than SPO, so the efficiency of PSO was greater than SPO in treating median-rigid cases. The reasons can be explained from two aspects. First, every PSO was single-level, but 9 out of 120 SPO cases were double-level, so the correction angle of a single-level SPO was smaller if we excluded the double-level cases. Second, even if the severe-rigid cases were included, PSO still had a larger correction angle than SPO. If PSO is used to cure mild-to-median rigidness, the correction angle should not decrease. On the other hand, the correction angle of SPO is difficult to increase during the treatment of severe stiffness. PWO had a larger correction efficacy than SPO because PWO involves more segments. Because PWO wins by the sheer quantity of surgical levels, the outcome is unlikely to change in median-rigid cases (Fig. 6).

The correction angles of some individual cases were quite extreme, such as $52^{\circ}$ for SPO [15] and $60^{\circ}$ for SPO $[2,24]$. As the angle increases, the incidence of complications increases. Wide-angle SPO usually causes lethal bleeding by aortic damage. In all 9 included studies, only Arun [22] reported one death. This reflects the fact that surgeons clearly know of the problem and paid great attention to avoid such a danger. Arun [22] emphasized the importance of a slow and careful operation during the "opening" process. In other words, do not let the "click" sound occur. The sound "click" came from the fracture of bone when spine was pulled backwards rapidly. Chang [19] did not suggest performing SPO on the elderly, advanced AS patients, or patients with arteriosclerosis. Chang [19] and Arun [22] considered SPO to be relatively suitable for L2 and lower levels, and malleable rods were necessary to offer temporary stability in the case of a correction greater than $35^{\circ}$. Because each method has its limitations, seeking a one-step correction in a single level is very dangerous. Bridwell [18]

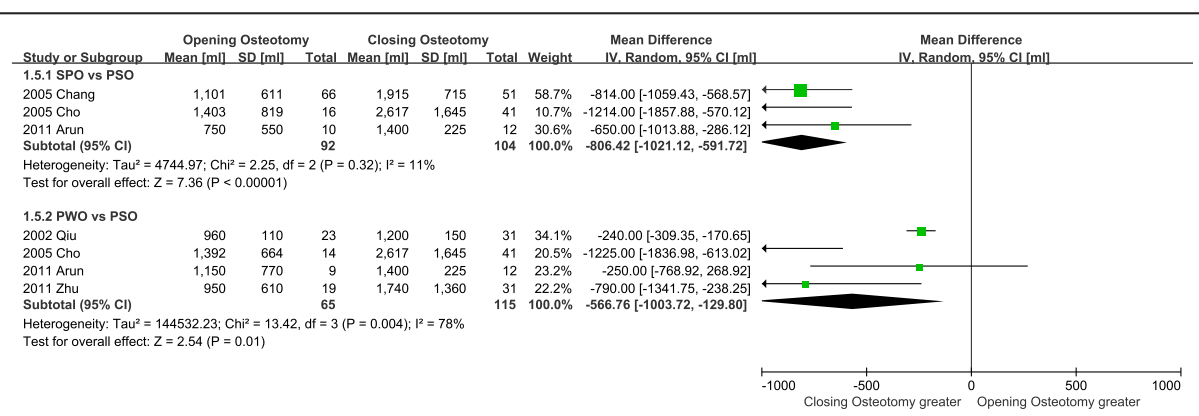

Fig. 4 Comparison of blood loss; Cl, confidence interval. Information: Both SPO and PWO had fewer blood loss than SPO 


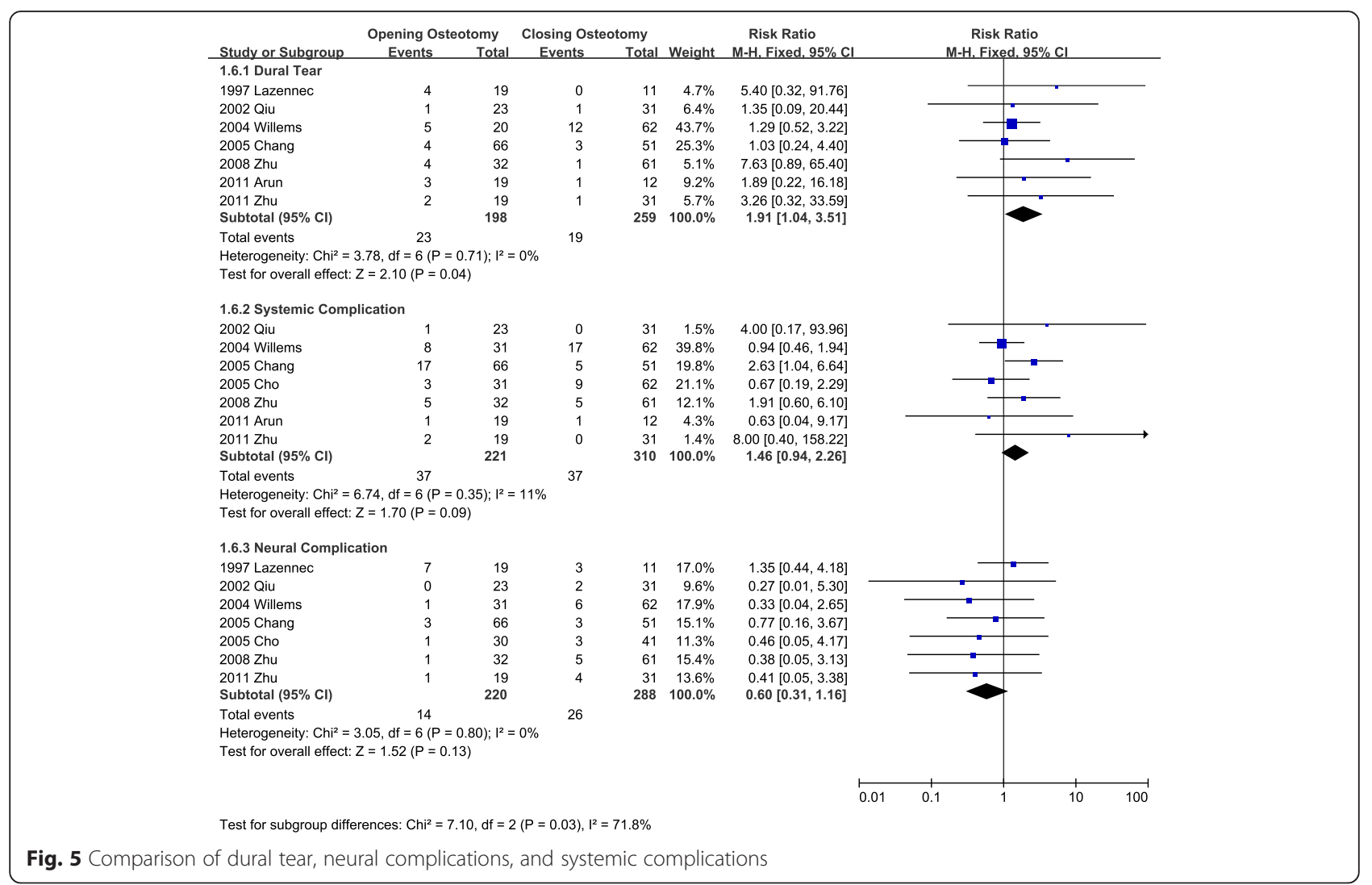

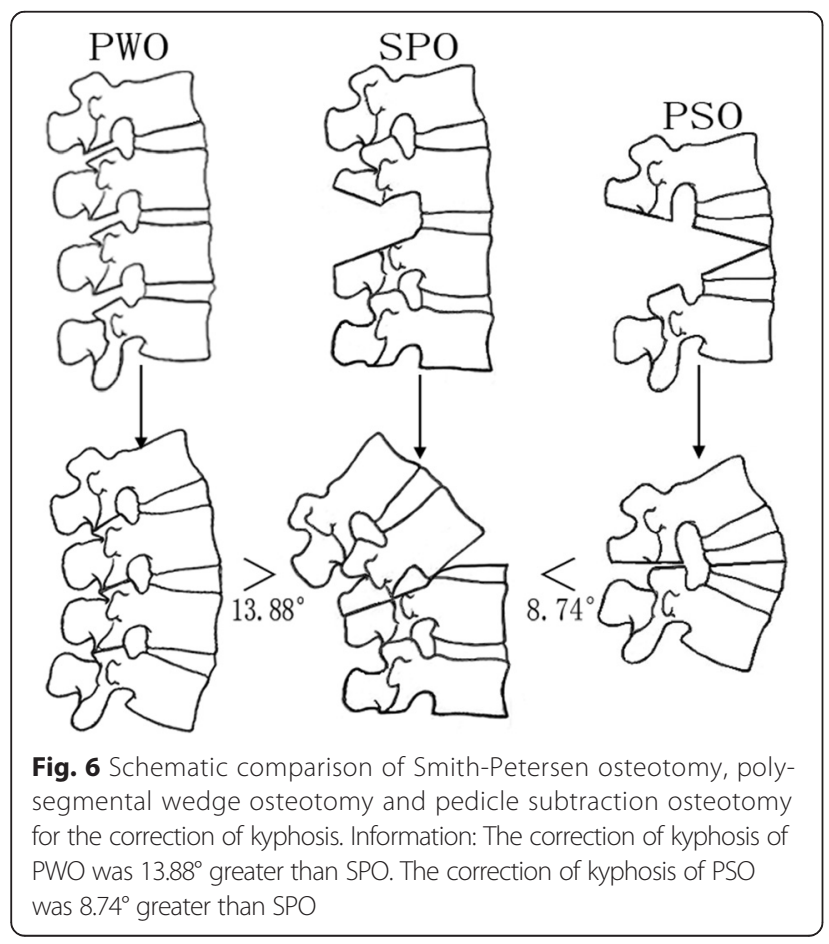

suggested combining one PSO and several PWOs together. SPO and PWO are not essentially different, except for the quantity of levels.

Local biomechanical complications included vertebral body translation, pedicle fraction, pedicle screw loosening, instrument breakage, nonunion, and anterior cortex fracture. They are mostly caused by improper fixation, miss operation or excessive elastic stress. PWO has a higher incidence of local biomechanical complications than PSO because PWO needs to overcome a greater stress of the spine. For mild-rigid cases, PWO would be more difficult in the median-rigid cases. On the contrary, using PSO to treat median-rigid cases should be easier compared to the severe cases reported by the pooled four studies. In other words, the rigidness of the spine affects PWO much more than PSO. Of the fixation materials, the Universal Spine System (USS) was stronger $[15,17]$ than the slender rod. Royen [25] reported that the instrumentation failure rate in PWO (6.5\%) was higher than PSO (3.8\%), which was close to our findings. Zhu [20] reported that the rate of correction loss in follow-up during opening osteotomy was $6.1^{\circ} \pm$ $6.7^{\circ}$, while that of the closing osteotomy was $1.3^{\circ} \pm 5.4^{\circ}$. Surgeons $[15,23]$ found that high anterior column tension, osteoporosis and progression of AS were too difficult and dangerous to perform for opening osteotomy because the implementation of SPO and PWO rely on a 
powerful pivot (posterior margin of vertebrae) to get the anterior column to open.

Blood loss in PSO was $800 \mathrm{ml}$ greater than in SPO and $550 \mathrm{ml}$ greater than in PWO. The large amount of blood loss in PSO was due to deeply cutting the vertebrae and difficulty in hemostasis. The key steps of PWO and SPO are the resection of the disc and zygapophyseal joint, during which bleeding would not be as many of a problem. In addition, PSO is more frequently used in severe-rigid cases. Thus, the more rigid the bone is, the more fragile the vessel becomes. As such, closing osteotomy should be carefully performed on the elderly and patients with a low tolerance to hemorrhage.

Some non-significant but highly consistent pooled outcomes appeared as well. In the analysis of local biomechanical complications, every individual study consistently presented that the incidence in SPO was greater than PSO. It is very likely that a meaningful outcome would be found if more articles were included or if each included study had a smaller standard deviation (high uniformity). We considered the incidence of local biomechanical complications in SPO to be higher than in PSO in median-rigid cases.

Cho [18] found better improvement in the sagittal vertical axis (SVA) in PSO than in PWO after the same angle of correction because PSO swings the upside vertebral column backward, and PWO twists it instead. He recommended using PSO to treat a SVA greater than $12 \mathrm{~cm}$. Daubs [26] thought that $10 \mathrm{~cm}$ was more reasonable.

The incidence of systemic complications was nearly the same in each individual study. The causes, such as inflammatory status of AS, medical co-morbidity, and perioperative management, might be complicated. Multifactor regression analysis and the inclusion of more related articles are needed for further analysis. Dura mater tearing is caused by vertebral translation [25] and careless clamping off of the calcified ligamentum flavum.

The spinal cord and nerve root are likely to be injured during the transformation of kyphosis. Royen [25] and Lazennec [15] believed that PSO did less harm to the nerve root because the previous steps, laminoplasty and intervertebroplasty, generally broadened the nerve root canal. However, PSO is not a good option for the spinal cord. A PSO greater than $40^{\circ}$ would increase the probability of spinal cord compression by shortening the posterior column [27]. Chang [19] did not encounter such problems even during PSOs of greater than $45^{\circ}$. He thought careful manipulation and the high tolerance of the medullary cone to compression were helpful. By calculating the height of a normal lumbar vertebral body, some surgeons consider that a PSO greater than $35^{\circ}[19,28,29]$ was difficult to achieve theoretically in one level due to greater nerve injury risk. The angle approaches our result $\left(36^{\circ}\right)$.

\section{Conclusions}

The "median-rigid" was not an exact quantified degree, but just the remaining cases without prominent features of stiffness that could not be recognized by doctors in decision making. The authors mainly discussed the operation choose for these cases. The authors closely combined surgeon's specialized knowledge with evidence-based data in order to help make right operation decisions. Median-rigid cases can be treated by either opening or closing osteotomy; PSO is more effective and efficient than SPO, and PWO is more efficient than SPO. PSO is suitable for high-degree kyphosis. Its advantages are little harm to the aorta, small demand on bone density, and low risk of instrumentation failure. However, substantial blood loss and the complicated surgical technique are two factors doctors should seriously consider. Comparing with SPO, PWO is proper for large angle kyphosis, but doctors must overcome such high risk of instrumentation failure. SPO is really good for small angle. Careful work is necessary to avoid aorta damage and middle column fracture. There are some limitations to this study. $\mathrm{I}^{2}$ value more than $50 \%$ is customarily considered to be high heterogeneity between studies. The $\mathrm{I}^{2}$ value in the correction angle comparing $\mathrm{PSO}$ vs $\mathrm{SPO}$ is $92 \%$. By now it is inappropriate to remove any articles no matter from professional judgement or the weight each possesses, because too few are included. To reduce the confounding effect of high heterogeneity, we used random mode which was supposed to give a very conservative result that not easy to make sense. The correction angle of SPO and PSO was regarded to be different in case the result under random mode still showed significance, and that was the fact. However, low heterogeneity degrade the level of evidence. To recognize and eliminate the bias completely, an RCT was needed. With the publication and enrollment of more new studies, these conclusions will become more convincing.

\section{Abbreviations \\ ALL: anterior longitudinal ligament; CO: closing osteotomy; NOS: Newcastle- Ottawa scale; OO: opening osteotomy; PSO: pedicular subtraction osteotomy; PWO: poly-segmental wedge osteotomy; RCT: randomized controlled trial; RR: risk ratio; SPO: smith-petersen osteotomy; TKD: thoracolumbar kyphotic deformity.}

\section{Competing interests}

The author (s) declare that they have no competing interests.

\section{Authors' contributions}

$\mathrm{HX}$ and CZ: acquisition, analysis or interpretation of data. WP, HL, and TY took part in the research design. YJ, CK, and AJT revised the article. SH approved and submitted the final version. All authors have read and

approved the final submitted manuscript.

\section{Acknowledgements}

This study was financially supported by the National Natural Science

Foundation of China (81271951, 81401850), and the Engineering Technology 
Research Center of Guangdong province (GCZX-A1301). There are no authors or financial affiliations that may be perceived to have biased this work.

\section{Author details}

'Department of Spine Surgery, Sun Yat-Sen Memorial Hospital, Sun Yat-Sen University, 107\# Yanjiangxi Road, Guangzhou 510120, P.R. China.

2Department of Neurosurgery, Sun Yat-Sen Memorial Hospital, Sun Yat-Sen University, Guangzhou, P.R. China.

Received: 27 September 2015 Accepted: 21 December 2015 Published online: 22 January 2016

\section{References}

1. Hehne HJ, Zielke K, Bohm H. Polysegmental lumbar osteotomies and transpedicled fixation for correction of long-curved kyphotic deformities in ankylosing spondylitis. Report on 177 cases. 1990.

2. Simmons EH. Kyphotic deformity of the spine in ankylosing spondylitis. Clin Orthop Relat Res. 1977;128:65-77.

3. Pigge RR, Scheerder FJ, Smit TH, Mullender MG, Van Royen BJ. Effectiveness of preoperative planning in the restoration of balance and view in ankylosing spondylitis. Neurosurg Focus. 2008;24, E7.

4. McMaster MJ. A technique for lumbar spinal osteotomy in ankylosing spondylitis. J Bone Joint Surg (Br). 1985;67:204-10.

5. Smith-Petersen MN, Larson CB, Aufranc OE. Osteotomy of the spine for correction of flexion deformity in rheumatoid arthritis. Clin Orthop Relat Res. 1969;66:6-9.

6. La CHAPELLEEH. Osteotomy of the lumbar spine for correction of kyphosis in a case of ankylosing spondylarthritis. J Bone Joint Surg Am. 1946;28:851-8.

7. Briggs $H$, Keats $\mathrm{S}$, Schlesinger PT. Wedge osteotomy of the spine with bilateral intervertebral foraminotomy; correction of flexion deformity in five cases of ankylosing arthritis of the spine. J Bone Joint Surg Am. 1947;29:1075-82.

8. Wilson PJ, Levine DB. Compensatory pelvic osteotomy for ankylosing spondylitis. A case report. J Bone Joint Surg Am. 1969;51:142-8.

9. Püschel J, Zielke K. Korrekturoperation bei Bechterew-Kyphose-Indikation, Technik, Ergebnisse. Zeitschrift für Orthopädie und Unfallchirurgie. 1982;120:338-42.

10. Thomasen E. Vertebral osteotomy for correction of kyphosis in ankylosing spondylitis. Clin Orthop Relat Res. 1985;194:142-52.

11. Howick J, Chalmers I, Glasziou P, Greenhalgh T, Heneghan C, Liberat A, et al. The Oxford 2011 Levels of Evidence, vol. 2013. 2011.

12. Higgins JPT, Altman DG, Gøtzsche PC, Jüni $P$, Moher D, Oxman AD, et al. The Cochrane Collaboration's tool for assessing risk of bias in randomised trials. BMJ. 2011;343.

13. Stang A. Critical evaluation of the Newcastle-Ottawa scale for the assessment of the quality of nonrandomized studies in meta-analyses. Eur J Epidemiol. 2010;25:603-5.

14. Collaboration TNCC. Review Manager. In: Version 5.1.4 edn. Copenhagen: Collaboration TNCC; 2011.

15. Lazennec JY, Saillant G, Saidi K, Arafati N, Barabas D, Benazet JP, et al. Surgery of the deformities in ankylosing spondylitis: our experience of lumbar osteotomies in 31 patients. Eur Spine J. 1997;6:222-32.

16. Qiu Y, Zhu Z, LV J, Wang B, Yu Y, Zhu L. Clinical comparison of two different osteotomy correction techniques for kyphosis deformity of ankylosing spondylitis. Chinese Journal of Orthopaedics. 2002;18:21.

17. Willems KF, Slot GH, Anderson PG, Pavlov PW, De Kleuver M. Spinal osteotomy in patients with ankylosing spondylitis: complications during first postoperative year. Spine (Phila Pa 1976). 2005;30:101-7.

18. Cho KJ, Bridwell KH, Lenke LG, Berra A, Baldus C. Comparison of SmithPetersen versus pedicle subtraction osteotomy for the correction of fixed sagittal imbalance. Spine (Phila Pa 1976). 2005;30:2030-7. 2038.

19. Chang KW, Chen YY, Lin CC, Hsu HL, Pai KC. Closing wedge osteotomy versus opening wedge osteotomy in ankylosing spondylitis with thoracolumbar kyphotic deformity. Spine (Phila Pa 1976). 2005;30:1584-93.

20. Zhu Z, Qiu Y, Wang B, Yu Y, Qian B, Zhu F, et al. Perioperative complications of osteotomy correction for thoracolumbar kyphosis in ankylosing spondylitis:a comparison between polysegmental wedge osteotomies and transpedicular wedge osteotomy. Chinese Journal Of Spine And Spinal Cord. 2008;18:895-9.
21. Dabke HV, Mehdian S, Debnath UK. Analysis of Sagittal Alignment Correction in Ankylosing Spondylitis Using Three Different Osteotomy Techniques. Journal of Bone \& Joint Surgery, British Volume. 2009;91:479-80.

22. Arun B, Dabke $\mathrm{H}$, Mehdian $\mathrm{H}$. Comparison of three types of lumbar osteotomy for ankylosing spondylitis: a case series and evolution of a safe technique for instrumented reduction. Eur Spine J. 2011;12:2252-60.

23. Zhu Z, Wang X, Qian B, Wang B, Yu Y, Zhao Q, et al. Loss of correction in the treatment of thoracolumbar kyphosis secondary to ankylosing spondylitis: a comparison between Smith-Petersen osteotomies and pedicle subtraction osteotomy. J Spinal Disord Tech. 2012;25:383-90.

24. Styblo K, Bossers GT, Slot GH. Osteotomy for kyphosis in ankylosing spondylitis. Acta Orthop Scand. 1985;56:294-7.

25. Van Royen BJ, De Gast A. Lumbar osteotomy for correction of thoracolumbar kyphotic deformity in ankylosing spondylitis. A structured review of three methods of treatment. Ann Rheum Dis. 1999;58:399-406.

26. Daubs M. Osteotomies for Adult Deformity: Surgical Techniques. Oper Tech Orthop. 2011:21:213-24.

27. Berven SH, Deviren V, Smith JA, Emami A, Hu SS, Bradford DS. Management of fixed sagittal plane deformity: results of the transpedicular wedge resection osteotomy. Spine (Phila Pa 1976). 2001;26:2036-43.

28. Gertzbein SD, Harris MB. Wedge osteotomy for the correction of posttraumatic kyphosis. A new technique and a report of three cases. Spine (Phila Pa 1976). 1992;17:374-9.

29. Leatherman KD, Dickson RA. Two-stage corrective surgery for congenital deformities of the spine. J Bone Joint Surg (Br). 1979;61-B:324-8.

\section{Submit your next manuscript to BioMed Central and we will help you at every step:}

- We accept pre-submission inquiries

- Our selector tool helps you to find the most relevant journal

- We provide round the clock customer support

- Convenient online submission

- Thorough peer review

- Inclusion in PubMed and all major indexing services

- Maximum visibility for your research

Submit your manuscript at www.biomedcentral.com/submit
) Biomed Central 